\title{
Function of Family-of-origin Experiences and Marital Adjustment among Married Iranian Students of Universiti Putra Malaysia
}

\author{
Soudabeh Ghoroghi ${ }^{1}$, Siti Aishah Hassan ${ }^{1} \&$ Maznah Baba ${ }^{1}$ \\ ${ }^{1}$ Faculty of Educational Studies, Department of Counselor Education and Counseling Psychology, Universiti \\ Putra Malaysia, Selangor, Malaysia \\ Correspondence: Soudabeh Ghoroghi, Faculty of Educational Studies, Department of Counselor Education and \\ Counseling Psychology, Universiti Putra Malaysia, 43400 UPM Serdang, Selangor, Malaysia. Tel: \\ 60-173-675-420. E-mail: sudygh@yahoo.com
}

Received: March 28, 2012

doi:10.5539/ijps.v4n3p94
Accepted: August 6, $2012 \quad$ Online Published: August 22

URL: http://dx.doi.org/10.5539/ijps.v4n3p94

\begin{abstract}
The purpose of this study was to examine the relationships between family-of-origin experiences and marital adjustment in a sample of married postgraduate Iranian students in Malaysia. The sample consisted of 220 married students who were randomly recruited to participate in the study through their email addresses. The respondents completed demographic information and two questionnaires including Family-of-Origin Scale (FOS; Hovestadt, et al., 1985) and the Locke-Wallace Marital Adjustment Test (LWMAT; Locke \& Wallace, 1959). A correlational survey design was utilized in the present study. Data analysis included frequencies, percentages, mean scores, Pearson's correlation, and multiple regression analysis. The results indicated that Family-of-origin experiences were positively and significantly correlated with marital adjustment. In addition, this study indicated that marital adjustment influences by family-of-origin experiences.
\end{abstract}

Keywords: family of origin, relationships, marital adjustment, married Iranian

\section{Introduction}

Undoubtedly, one of the most important decisions for most individuals, if not all, is choosing a marital partner, especially among traditional societies and families. Marriage is defined as a formally-written, verbal, or tradition long-term agreement between a man and a woman for the production of children, food and other commodities in a domestic context (Bailey, 2003).

In a marriage, marital satisfaction refers to the level of satisfaction or happiness derived from the union (Locke \& Wallace, 1959). The level of marital satisfaction determines the survival of any marriage and as such there have been studies and investigations on the factors that affect marital satisfaction since the 1990s (Bradbury, Fincham, \& Beach, 2000). According to Snyder and Lopez (2005), marital bliss contributes to enhanced well-being and a happy marriage experiences less stress, anxiety or depression. It is therefore understandable why there has been much focus on investigating the key factors that lead to happy marriages.

The process in which an individual or a couple modifies, adopts or changes their behavior pattern and interaction to gain the maximum satisfaction in their relationship is referred to as marital adjustment (Bali, Dhingra, \& Baru, 2010). Marital adjustment, which is a developmental process (Martin, 2007) has been investigated extensively in marriage and family relationship research and it is one of the most frequently investigated dependent variables in relationship studies.

According to Martinson (2005), of the various factors that influence the development and behavior of an individual e.g., socio-cultural interactions and environment, work, friends, etc, family-of-origin experiences that we go through with our family have the greatest impact. According to Hovestadt, and colleagues (1985), family-of-origin is the family of an individual's psychological, physical and emotional beginnings. The term experiences in the family-of-origin, refers to person's experiences with parents and/or primary caregivers and especially the relationship with the parents during childhood, as the basis of relationships in adult life (Falcke, Wagner, \& Mosmann, 2008).

Kerr (2008) reminds us that while we are physically away from our family, we do not leave them emotionally. From a multigenerational perspective, the legacy of the family of origin appears to be unshakably with us, an 
emotional baggage that stubbornly stays within us that is exhibited in our adult relationships (Martinson, 2005; Sabatelli \& Bartle, 2003). As such, the circumstances of the family-of-origin determine the conjugal adjustment and the psycho-social state of the individual in later life (Asadinik, 2009; Botha, Berg, \& Venter, 2009; Falcke, et al., 2008; Luecken, Kraft, \& Hagan, 2009; Martinson, 2005; Topham, Larson, \& Holman, 2005).

The importance of the family of origin is unavoidable. This is why Falcke et al. (2008) stated that the basis of conjugal choice is related to the inclination to replicate the family-of-origin. As such, instead of mutual agreement between both partners on what should be, there is the conflict that arises from one party trying to impose his/her perspective on the other in their individual efforts to recreate their personal family-of-origin, their own cultural and familiar patterns. Similarly, Patterson, Williams, Edwards, Chamow, and Grauf-Grounds (2009) make the same conclusions and advice therapists and counselors when doing marital or couple therapy to closely assess the couples' family-of-origin. Carr (2006) indicated that family-of-origin and parent-child experiences may lead individuals to hold on to certain belief systems and patterns of behavior that contribute to marital discord such as attachments that are insecure, and authoritarian, permissive, neglectful or inconsistent parenting. It has been indicated that it is not easy to come to terms with the internalization of anger, devotion, loyalty and neglect that originated in the family-of-origin (Laham, 1990).

In the discussions on parent-adolescent relationships, theorists stressed that adolescents should be detached from their parents emotionally so that they can become autonomous and independent individuals (Steinberg \& Silverberg, 1986). Allen et al. (1994) emphasized that for healthy adolescent development, a balance between autonomy and relatedness in the parental relationships should be maintained. Intimacy and autonomy are two essential conditions for an optimal functioning of a marriage (Gordon, 2006).

The perceptions of marital satisfaction vary across cultures (Atta-Alla, 2009). In a recent research by Delkhamoush (2007), his findings showed that the content and structure of young Iranians' marital values could be explained by the five dimensions of Schwartz and Ros' (1995) theoretical model of values. He further concluded that Iranian youths' perception of conceptual values of marriage is the same as the common perspective in other societies (Delkhamoush, 2007).

In traditional Iranian culture, the primary goal of marriage is procreation such that infertility is sufficient grounds for divorce (Asadinik, 2009). Zoroastrians in ancient Iran made marriage vows for life and there were rare divorces among them (Kameli, 2008). In case of conflict or disagreement, the couple's families and priests helped to resolve the conflict. Unavoidable divorce brought shame and dishonor to the families until recently. Islam discourages divorce and considers it as the last resort for the couples who cannot continue a healthy relationship (Kameli, 2008).

Many Iranian couples endure a problematic marriage for the sake of the family and self-sacrifice of personal freedoms and happiness for the sake of the family has always been highly valued in traditional Iranian culture (Asadinik, 2009). However, over the past few decades, relationship patterns have become more diverse. There are a lot of marriage-related issues researched that indicate changes in marital values. The results of studies show mate selection has changed in both industrial countries (Higgins, Zheng, Liu, \& Sun, 2002; Kiernan, 2000; P. D. Martin, Specter, Martin, \& Martin, 2003), and developing countries (Delkhamoush, 2007; Zaidi \& Shuraydi, 2002). Many rapid global changes that are occurring have had an impact on patterns of marriage in developing countries (Delkhamoush, 2007).

Dennison (2011) carried out a mixed methods study and investigated how family-of-origin characteristics (inter-parental conflict) influenced the state of current marriage on 190 newly-wed couples in Arizona USA. It was found that family-of-origin characteristics (inter-parental conflict) that were measured indicated a reduction in the level of marital satisfaction, particularly among wives. especially Sabatelli and Bartle (2003) study that investigated 125 newly-wed student couples at Ohio State university and evaluated the correlation between the experiences of the newly-weds' experiences in their family-of-origin and how they coped with their marriage. The data analysis indicated that the family-of-origin experiences of both partners significantly influenced their own marriage adjustments.

A total of 542 respondents in Porto Alegre, Brazil were studied by Falcke,et al. (2008) using Family Background Questionnaire (FBQ) and the Golombok Rust Inventory of Marital state (GRIMS). Results showed a relationship between level of marital satisfaction and their family-of-origin influences. With the aim of exploring the relationship between marital satisfaction and family-of-origin, Botha et al. (2009) from South Africa used Locke and Wallace's Marital Adjustment Test and the McMaster Family Assessment Device on 47 married couples. Again it was found that there was a close association between family-of-origin factors and the status of married life. The researchers also investigated the significance of family-of-origin functions as a determining aspect of 
the quality of later married life.

A research conducted on 6,423 U.S. couples by Martinson (2005) indicated that those among the respondents who had desirable family-of-origin experiences, also had more satisfying married lives while those who had less satisfactory family-of-origin histories showed less satisfaction with their marriage.

Shokrkon, Khojastemehr, Atari, Haghighati, and Shahniyeilagh (2006) investigated the predictors of marital relationship in divorced couples compared to normal ones among 514 respondents in Ahwaz city in Iran. Utilizing multiple regression, the findings indicated that personality factors, social skills and family-of-origin characteristics (attachment styles) have a relationship with marital adjustment.

The factor influencing marital satisfaction can be external stressors while studying abroad. As opposed to domestic students with more social support, Hechanova-Alampay, Beehr, Christiansen, and Horn (2002) believe that international students suffer from additional stress, loneliness, homesickness and finally anxiety. According to the Ministry of Higher Education, the flow of international postgraduate students to Malaysian universities has increased in the years 2002 to 2008 from 27,872 to 90,501(Horany \& Hassan, 2011). Iranian postgraduate students seem to outnumber others in Malaysian public universities (Akhtari-Zavare \& Ghanbari-baghestan, 2010). However, most studies on post graduate students in Malaysia focus on their academic enhancement and supervision (Ibrahim \& Hassan, 2011; Krauss \& Ismail, 2010), only few studies focus on the marital life of these students (Kalantarkousheh \& Hassan, 2010).

\section{Methodology}

\subsection{Respondents and Procedure}

The respondents included in this study were married postgraduate Iranian students in Universiti Putra Malaysia. Students were randomly recruited to participate in the study through their emails addresses. The target population of the study comprised all postgraduate married Iranian students enrolled in governmental universities encompassed almost all postgraduate Iranian students. The target university of this Study was Universiti Putra Malaysia (UPM) which is classified as governmental by classification of the Malaysian Ministry of Higher Education (MOHE, 2011). The Iranian Students Association Malaysia states that this university has 1,760 students enrolled in master and Ph.D programs, making it the Malaysian public university with the highest number of Iranian postgraduate students (ISAM, 2011). The minimum sample size regarding G*Power is 172, and according to Bartlett, Kotrlik, and Higgin (2001), it is 100. Thus in this study, the target number of 220 subjects was calculated to ensure the reliability of the study. A list of Iranians who meet the eligibility criteria was obtained from the School of Graduate Studies of UPM (SGS). The whole married postgraduate population of Iranian students and their individual email addresses was 600 subjects. Using simple random sampling, 300 random digit selected because of non-responded, non-completed probability consideration of respondents. Data for this study were obtained by administering the survey instruments to the respondents via an online survey. The total number of respondents reached 220. The raw data from the online survey instruments were downloaded from the website in which the survey was administered and imported into a computer spreadsheet for analysis. The sample consisted of 220 married students including 117 females and 107 males aged from 25 to 61 .

\subsection{Instrumentation}

In addition to the demographic questionnaire, two instruments were used to collect the data. Both of the items were translated into Farsi to make it feasible for administration to respondents. The translation was done by a panel of experts under supervision of Sanai (one of the most well-known professors in Family and Marriage Counseling and psychotherapy) and printed in a book titled "Family and Marriage Scales" in the year 2009. The translated versions have been frequently used in different studies in Iran (Bahari et al., 2010). The instruments include:

\subsubsection{Family-of-Origin Scale (FOS; Hovestadt, et al., 1985)}

The adolescent FOS scale is an instrument designed to measure the "perceived levels of health in one's family-of-origin" (Hovestadt, et al., 1985). In contrast to other self-report measures of family functioning, the FOS provides a unique perspective particularly relevant to adolescent development (Manley, Wood, Searight, Skitka, \& Russo, 1994). This 5-point Likert-type scale consists of 40-items which, according to the test authors Hovestadt et al. (1985) tap 10 relational characteristics that are thought to influence an individual's capacity regarding the two dimensions of autonomy and intimacy. Twenty of the items are designed to measure autonomy and the other 20 items are designed to measure the encouragement of intimacy. The autonomy dimension is comprised of five subscales: Clarity of Expression - thoughts and feelings are clear in the family; Responsibility - family members claim responsibility for their own actions; Respect for Others - family members are allowed to 
speak for themselves; Openness to Others - family members are receptive to one another; Acceptance of Separation and Loss - separation and loss are dealt with openly in the family. The intimacy dimension consists of five subscales: Range of Feelings - family members express a wide range of feelings; Mood and Tone - a warm positive atmosphere exists in the family; Conflict Resolution - normal conflicts are resolved without undue stress; Empathy - family members are sensitive to one another; and Trust. With a range of possible scores 40-200, high scores (160-200) on this scale indicate higher perceived family-of-origin health, while low scores (40-80) indicate lower perceived health. Some examples of questions are "My parents openly admitted it when they were wrong." and "Sometimes in my family I did not have to say anything, but I felt understood".

Mazer, Mangrum, Hovestadt and Brashear (1990), based on their testing of family-of-origin scale with 407 adolescent participants, found that the scale is a multi-dimensional tool with value and validity to be applied in clinical research. Fischer and Corcoran (2007) report the internal consistency of the family-of-origin scale as .75, and a test-re-test reliability of .77 for measures of autonomy, and .73 for measures of intimacy. In the current study, reliability for FOS was a $=.925$.

\subsubsection{The Locke-Wallace Marital Adjustment Test (LWMAT; Locke \& Wallace, 1959)}

This instrument was developed to measure the marital happiness or marital satisfaction in married couples. Using selected, non-duplicated and statistically significant items from a variety of previously developed measures with high item discrimination, Locke and Wallace (1959) composed a 15-item marital adjustment scale. Because of its history and widespread use, it is used as a benchmark standard for assessing the degree of adjustment in marriage (Sperry, 2004). The LWMAT has a total of 15 questions that are ranked on different scales. The main scale that is provided on the LWMAT is a 6-point Likert-type scale that has a minimum score of 1, representing "Always Disagree," and a maximum score of 6, representing "Always Agree". The remaining questions that are provided on the LWMAT include multiple choice type responses. Some examples of these questions are, "When disagreements arose, they usually resulted in (a) husband giving in (b) wife giving in (c) agreement by mutual give and take" and "If you had your life to live over again, do you think you would: (a) Marry the same person? (b) Marry a different person (c) Not marry at all".

The validity of the LWMAT was illustrated by Krokoff (1989) using predictive validation. It was found that the scores for the husbands and wives in the sample had significant correlations with one another. The reliability of the LWMAT instrument was illustrated with internal consistency/reliability coefficients using Cronbach's alpha scores. In the original study by Locke and Wallace (1959), it was found that the reliability of the LWMAT was equal to .90 (Sanai, 2009). In the current study, reliability for LWMAT was $\alpha=.819$.

\subsection{Data Analysis}

The data analysis used in this study was the descriptive statistics to sum up data and report percentages and frequencies. Additionally Pearson's correlation coefficient was used to estimate the relationship between independent variable (family-of-origin experiences), and dependent variable (marital adjustment). Furthermore multiple regression used to examine the accurate prediction of a predictor.

\section{Results}

\subsection{Descriptive Statistics}

Table 1 shows that $54.1 \%$ of participants are within the age range of $25-35$ years while $40.9 \%$ are between $36-45$ years of age. A majority of the participants were doctoral students (58.2\%) and $41.8 \%$ were doing their master's degree. In terms of marriage duration, $86.8 \%$ of participants were within 1-17th year of their marital life and only $13.2 \%$ of them were living with their spouses between $17-34$ years. With regard to the number of children, $42.3 \%$ of the respondents do not have children, $34.5 \%$ of them have one child, and $18.7 \%$ have two children while only $4.5 \%$ have three children. 
Table 1. Descriptive statistics for demographics variables, for the total sample and by gender

\begin{tabular}{|c|c|c|c|c|}
\hline & & $\begin{array}{l}\text { Percent for All } \\
(n=220)\end{array}$ & $\begin{array}{l}\text { Percent } \\
\text { For Males } \\
(n=107)\end{array}$ & $\begin{array}{l}\text { Percent } \\
\text { For Females } \\
(\mathrm{n}=113)\end{array}$ \\
\hline \multirow{5}{*}{ Age } & $25-35$ & 54.1 & 52.3 & 55.8 \\
\hline & $36-45$ & 40.9 & 42.1 & 39.8 \\
\hline & $46-60$ & 4.5 & 5.6 & 3.5 \\
\hline & 61 and more & .5 & 0 & .9 \\
\hline & Total & 100.0 & 100.0 & 100.0 \\
\hline \multirow{3}{*}{ Education } & Master & 41.8 & 28.0 & 54.9 \\
\hline & Doctoral & 58.2 & 72.0 & 45.1 \\
\hline & Total & 100.0 & 100.0 & 100.0 \\
\hline \multirow{3}{*}{$\begin{array}{l}\text { Duration of } \\
\text { Marriage }\end{array}$} & $1-17$ & 86.8 & 87.9 & 85.8 \\
\hline & $17-34$ & 13.2 & 12.1 & 14.2 \\
\hline & Total & 100.0 & 100.0 & 100.0 \\
\hline \multirow{5}{*}{$\begin{array}{l}\text { Number of } \\
\text { Children }\end{array}$} & 1 & 34.5 & 29.9 & 38.9 \\
\hline & 2 & 18.7 & 25.2 & 12.4 \\
\hline & 3 & 4.5 & 4.7 & 4.4 \\
\hline & None & 42.3 & 40.2 & 44.2 \\
\hline & Total & 100.0 & 100.0 & 100.0 \\
\hline
\end{tabular}

Table 2 presents the descriptive statistics of dependent and independent variables. Marital adjustment score has a minimum of 63 with a maximum of 138 from maximum score of $158(\mathrm{M}=100.58, \mathrm{SD}=15.83)$. Family-of-origin total scores ranged from 95 to 172 (the maximum is 200) and had a mean of 135.39 with a standard deviation of 14.25. Its sub-scales scores had a minimum of 5 with a maximum of 20 . In addition, it seems that the participants' function with the respect of responsibility was the weakest and their mood and tone were the strongest factors in the family-of-origin sub-scales.

Table 2. Descriptive statistics of marital adjustment and family-of-origin subscales

\begin{tabular}{ccccccc}
\hline Variables & $\begin{array}{c}\text { No. of } \\
\text { Items }\end{array}$ & Minimum & Maximum & Mean & $\begin{array}{c}\text { Std. } \\
\text { Deviation }\end{array}$ & $\begin{array}{c}\text { Cronbach's } \\
\text { Alpha }\end{array}$ \\
\hline Marital adjustment & 15 & 63.30 & 138.00 & 100.85 & 15.83 & .758 \\
Family-of-origin total & 40 & 95 & 172 & 135.39 & 14.25 & .815 \\
Clarity of Expression & 4 & 8.00 & 20.00 & 13.64 & 2.47 & .820 \\
Responsibility & 4 & 7.00 & 17.00 & 11.89 & 1.67 & .832 \\
Respect for Others & 4 & 7.00 & 18.00 & 13.22 & 2.04 & .824 \\
Openness to Others & 4 & 9.00 & 17.00 & 12.63 & 1.70 & .828 \\
Acceptance of & 4 & 5.00 & 20.00 & 14.31 & 2.67 & .828 \\
Separation and Loss & & & & & \\
Range of Feelings & 4 & 7.00 & 20.00 & 12.08 & 2.41 & .827 \\
Mood and Tone & 4 & 8.00 & 20.00 & 15.98 & 2.70 & .820 \\
Conflict Resolution & 4 & 6.00 & 20.00 & 13.22 & 3.01 & .817 \\
Empathy & 4 & 8.00 & 20.00 & 14.20 & 2.49 & .821 \\
$\quad$ Trust & 4 & 7.00 & 20.00 & 14.22 & 2.55 & .823 \\
\hline
\end{tabular}

Note: $n=220$ 


\subsection{Correlations}

In this step, the association between family of origin total scale and marital adjustment was examined through bivariate analyses. It was hypothesized that there is a significant relationship between family-of-origin scale and subscales and marital adjustment among married postgraduate Iranian students in Malaysia. Table 3 presents the Pearson correlation matrix. As it can be seen here, this table indicates that the family-of-origin total scale correlated significantly and positively with marital adjustment $(\mathrm{r}=.514, \mathrm{p}<.01 \mathrm{~N}=220)$. Among all the sub-scales more significantly correlated at .01 is conflict resolution with marital adjustment $(\mathrm{r}=.412, \mathrm{p}<.01, \mathrm{~N}$ $=220)$, trust $(\mathrm{r}=.387, \mathrm{p}<.01, \mathrm{~N}=220)$, and openness to others $(\mathrm{r}=.384, \mathrm{p}<.01, \mathrm{~N}=220)$. As was the case with total family-of-origin scores, this is a positive relationship, hence we can conclude that, the higher perceived family-of-origin health was defined, the higher level of marital adjustment the participants experienced.

Table 3. Correlations between the family of origin sub-scales and marital adjustment

\begin{tabular}{|c|c|c|c|c|c|c|c|c|c|c|c|c|}
\hline VAR & MA & FOS & CLE & RSP & RET & OPN & $\mathrm{ACP}$ & RAG & MOD & CFT & EMP & TST \\
\hline MA & 1 & & & & & & & & & & & \\
\hline FOS & $.514^{* *}$ & 1 & & & & & & & & & & \\
\hline CLE & $.295 * *$ & $.764 * *$ & 1 & & & & & & & & & \\
\hline RSP & $.234^{* *}$ & $.213 * *$ & 0.076 & 1 & & & & & & & & \\
\hline RST & $.381^{* *}$ & $.634 * *$ & $.383^{* *}$ & 0.122 & 1 & & & & & & & \\
\hline OPN & $.384 * *$ & $.469^{* *}$ & $.255^{* *}$ & $.151^{*}$ & $.286^{* *}$ & 1 & & & & & & \\
\hline $\mathrm{ACP}$ & $.141^{*}$ & $.432 * *$ & $.231 * *$ & -0.048 & $.173^{*}$ & 0.104 & 1 & & & & & \\
\hline RNG & $.153^{*}$ & $.512 * *$ & $.352 * *$ & 0.081 & $.289 * *$ & $.252 * *$ & $.225 * *$ & 1 & & & & \\
\hline MOD & $.322 * *$ & $.744 * *$ & $.525 * *$ & 0.077 & $.404 * *$ & $.236^{* *}$ & $.228^{* *}$ & $.210^{* *}$ & 1 & & & \\
\hline CFT & $.412^{* *}$ & $.763 * *$ & $.582 * *$ & 0.116 & $.413^{* *}$ & $.267^{* *}$ & 0.12 & $.242^{* *}$ & $.657^{* *}$ & 1 & & \\
\hline EMP & $.375^{* *}$ & $.704 * *$ & $.527^{* *}$ & 0.108 & $.418^{* *}$ & $.280^{* *}$ & $.273^{* *}$ & $.249 * *$ & $.495^{* *}$ & $.431^{* *}$ & 1 & \\
\hline TST & $.387^{* *}$ & $.579 * *$ & $.445^{* *}$ & -0.089 & $.328^{* *}$ & $.196^{* *}$ & 0.102 & $.139^{*}$ & $.363^{* *}$ & $.468^{* *}$ & $.302^{* *}$ & 1 \\
\hline
\end{tabular}

Note: Correlation is significant at the 0.01 level (2-tailed), ${ }^{*} \mathrm{p}<.05,{ }^{* *} \mathrm{p}<.01, \mathrm{n}=220 \mathrm{p}=0.1$ : small effect; $\mathrm{p}=0.3$ : medium effect; $\mathrm{p}=0.5$ : large effect Abbreviations: $\mathrm{MA}=$ marital adjustment; Family of Origin $\mathrm{Scale}=(\mathrm{FOS})$ : $\mathrm{CLE}=$ clarity of expression; $\mathrm{RSP}=$ responsibility; $\mathrm{RST}=$ respect for others; $\mathrm{OPN}=$ openness to others; $\mathrm{ACP}=$ acceptance of separation \& loss; $\mathrm{RNG}=$ range of feeling; $\mathrm{MOD}=\operatorname{mood} \&$ tone; $\mathrm{CFT}=$ conflict resolution; $\mathrm{EMP}=$ empathy; TST=trust

\subsection{Multiple Regression Analysis}

Multiple regression is a correlational procedure that examines the relationships among several variables. "Specifically, this technique enables researchers to find the best possible weighting of two or more independent variables" (Ary, Razavieh, Jacobs, \& Sorenson, 2010, p. 360). When two variables were correlated perfectly Ho (2006) states that multiple regresion provide an opportunity to assess the importance of each of the predictors to the overall relationship.

Using the enter method; findings can be seen at Table 4. The findings revealed that two of the predictor variables were significant in explaining the marital adjustment. The two predictors variables were autonomy $(t=3.398 ; p$ $=.001)$, and intimacy $(\mathrm{t}=3.647 ; \mathrm{p}=.000)$. The findings suggest that the data supported the two-predictor multiple linear regression model. 
Table 4. Multiple regression analysis

\begin{tabular}{llllllllll}
\hline Variables & $\begin{array}{l}\text { Summary Of } \\
\text { Regression }\end{array}$ & $\begin{array}{l}\text { Un-Std } \\
\text { Coefficient B }\end{array}$ & $\begin{array}{l}\text { Un-Std } \\
\text { Coefficient } \\
\text { Std. Error }\end{array}$ & $\begin{array}{l}\text { Std. } \\
\text { Coefficient } \\
\text { Beta }\end{array}$ & $\mathrm{T}$ & $\begin{array}{l}\text { Sig. } \\
\text { Value }\end{array}$ & \multicolumn{2}{c}{$\begin{array}{c}\text { Collinearity } \\
\text { Statistics } \\
\text { Tolerance }\end{array}$} & VIF \\
\hline (constant) & & 20.741 & 9.758 & & 2.125 & & & \\
Autonomy & & .688 & .202 & .271 & 3.398 & .001 & .533 & 1.876 \\
Intimacy & & .497 & .136 & .291 & 3.647 & .000 & .533 & 1.876 \\
Multiple R & .515 & & & & & & & & \\
R Square & .265 & & & & & & & & \\
Adjusted R & .259 & & & & & & & & \\
Square & & & & & & & & & \\
F-Statistics & 39.192 & & & & & & & & \\
\hline
\end{tabular}

Note. Predictors: (Constant), Autonomy \& Intimacy. Dependent variable: Marital Adjustment, $\mathrm{p}<.05, \mathrm{n}=220$

An R-square value of .265 implies that the two-predictor model explained about $26.5 \%$ of the variance in marital adjustment. Table 4 revealed that based on the reported value of the $F$-statistic $(F=39.192, p<.05)$, the model fits the data. This means that the slope of the estimated linear regression model line was not equal to zero, thus confirming that there was a linear relationship between marital adjustment and the two predictor variables.

Standardized regression coefficients are presented in Table 4. to explain the importance of two predictors in predicting marital adjustment. Independent variable with a high beta coefficient is highly important in contributing to the prediction of the criterion variable. Based on the beta values obtained, the beta coefficient for autonomy was .271 and for intimacy was .291 . This means that intimacy relatively had a higher power than the autonomy in predicting the marital adjustment. Also this describes that a one standard deviation increase in autonomy was followed by a .271 standard deviation unit increase in marital adjustment and that one standard deviation increase in intimacy was brought about a .291 standard deviation unit increase in marital adjustment

Furthermore, result in this study indicated that men's perception of marital adjustment is more influenced by their families of origin experiences than women's. In other words, for men $37.7 \%$ of the variance in marital adjustment increase was explained by family-of-origin experiences, while in women the overall regression model was successful in explaining approximately $17.9 \%$ of the adjusted variance in marital adjustment. Thus, family-of-origin experiences measured predicted marital adjustment especially for men (Table 5).

Table 5. Multiple regression analysis by gender

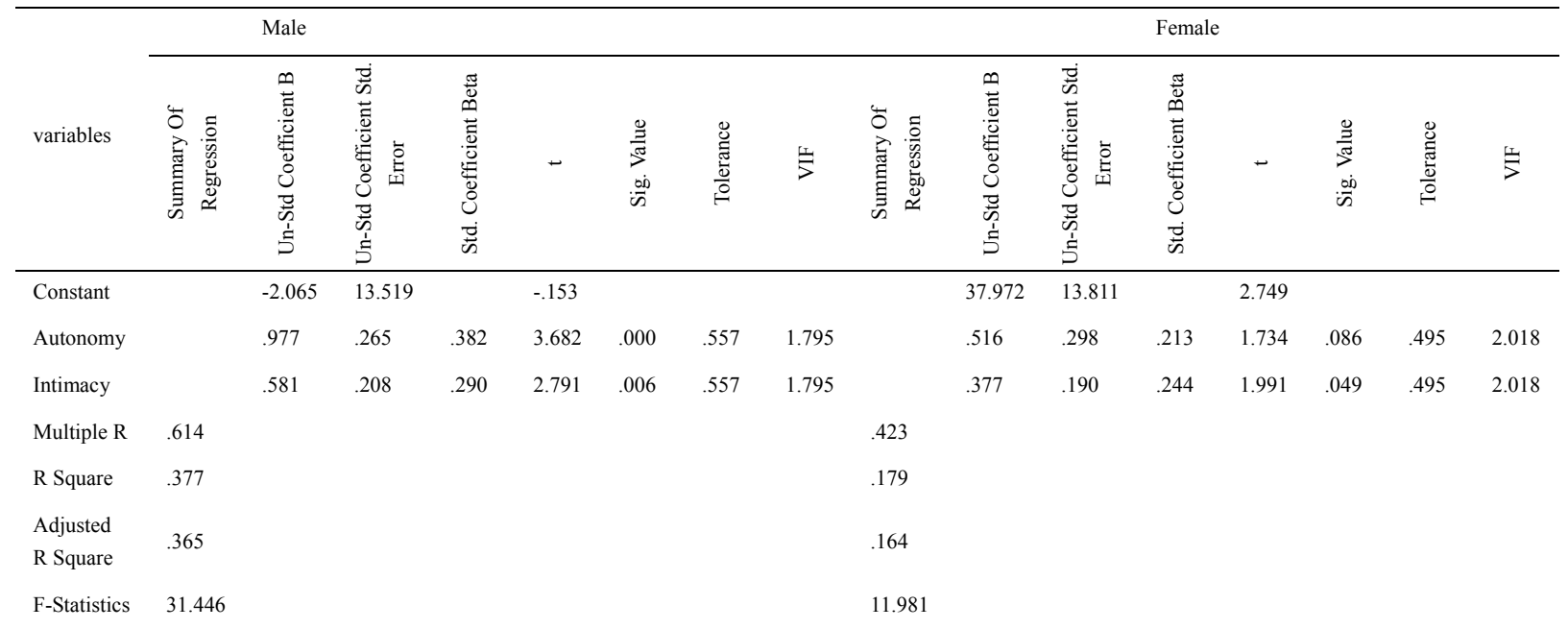

Note. Predictors: (Constant), Autonomy \& Intimacy. Dependent variable: Marital Adjustment, $\mathrm{p}<.05, \mathrm{n}=113$ female, $\mathrm{n}=107$ male 


\section{Discussion}

The results of present study clearly indicate that 1) Family-of-origin experiences were positively correlated to marital adjustment of respondents. This implies that despite living out of the country of origin, Iran, the post graduate students in Malaysia are still influenced by the family of origin and the collectivistic cultures. This finding is in agreement with the results of Falcke et al. (2008) which indicated that there is an association between type of experience that the respondents live in their families of origin and the quality of their marital relationship. Since, Iranian culture is similar to the host country Malaysia, in terms of being a collectivist society, the influence of family of origin remains significant. 2) The family-of-origin dimensions (autonomy and intimacy) were statistically significant predictors of the marital adjustment. Indeed, the autonomy and intimacy were found to be the best predictors of marital adjustment. In addition, result in this study indicated that men's perception of marital adjustment is more influenced by their families of origin experiences than women's. So, the findings of this study support the presence of positive effects of family-of-origin experiences on married students' marital adjustment. For example, in line with this finding, Dennison (2011) examined the effect of family-of-origin characteristics (e.g., interparental conflict) on current marital satisfaction, within a sample of newlywed. Findings of the study stress the need to help individuals understand the significance of their family-of-origin experiences in their later relationships, particularly in their married lives. The present investigation was concluded that the experiences from families of origin can influence marital quality and awareness about these experiences can play a significant role in enhancing the quality of marriage among married individuals.

The limitation of this study lies in use of correlational statistical approach in the study of married persons' memories of their past experiences within their families of origin. To overcome this limitation, future studies may consider longitudinal, observational and experimental research design to evaluate their needs and enhance and develop their educational and clinical training. Also, future research will need to assess both members of a couple rather than assessing each married person individually. We also suggest that future studies examine function of family-of-origin experiences and marital adjustment of different samples of non-academic and business settings and compare the results obtained.

\section{References}

Akhtari-Zavare, M., \& Ghanbari-baghestan, A. (2010). Iranian student's emotion in government university in Malaysia. Global Journal of Health Science, 2(2), 72-79.

Allen, J. P., Hauser, S. T., Bell, K. L., \& O’Connor, T. G. (1994). Longitudinal assessment of autonomy and relatedness in adolescent-family interactions as predictors of adolescent ego development and self-esteem. Child Development, 65, 179-194. http://dx.doi.org/10.2307/1131374

Ary, D., Razavieh, A., Jacobs, L. C., \& Sorenson, C. K. (2010). Introduction to research in education (9th ed.). Wadsworth Publishing Company.

Asadinik, S. (2009). Differentiation of self, marital adjustment, and parental involvement among Iranian-Americans. (Doctoral dissertation). Retrieved from ProQuest Dissertations and Theses. (Order No. AAT 3428758).

Atta-Alla, M. (2009). Perceptions of marital satisfaction among Coptic Orthodox Christian Egyptian-American husbands and wives. (Doctoral dissertation). Retrieved from ProQuest Dissertations and Theses. (Order No. AAT 3370909).

Bailey, J. (2003). Unquiet Lives: Marriage and marriage breakdown in England, 1660-1800. New York: Cambridge University Press.

Bahari, F., Fatehizade, M. S., Ahmadi, S. A., Moulavi, H., \& Bharami, F. (2010). The effect of hope, forgiveness and combined marital counseling on interpersonal cognitive distortions of divorcing couples. Journal of Research of Behavioral Science, 1(8), 25-33.

Bali, A., Dhingra, R., \& Baru, A. (2010). Marital adjustment of childless couples. J Soc Sci, 24(1), 73-76.

Botha, A., Berg, H. S. V. D., \& Venter, C. A. V. (2009). The Relationship between family of origin and marital satisfaction. Journal of Interdisciplinary Health Science, 14(1), 441-447.

Bradbury, T. N., Fincham, F. D., \& Beach, S. R. H. (2000). Research on the nature and determinants of marital satisfaction: A decade in review. Journal of Marriage and Family, 62(4), 964-980. http://dx.doi.org/10.1111/j.1741-3737.2000.00964.x

Carr, A. (2006). Family therapy; Concepts, process and practice. New York: Wiley 
Delkhamoush, M. T. (2007). Marital values of Iranian youth. Journal of Iranian Psychologists, 3(12), 299-309.

Dennison, R. (2011). The effect of family of origin on early marriage outcomes: A mixed method approach. (Doctoral dissertation). Retrieved from ProQuest Dissertations and Theses. (Order No. AAT 3432589).

Falcke, D., Wagner, A., \& Mosmann, C. P. (2008). The Relationship between family of origin and marital adjustment for couples in Brazil. Journal of Family Psychotherapy, 19(2), 170-186. http://dx.doi.org/10.1080/08975350801905020

Fischer, J., \& Corcoran, K. (2007). Measures for clinical practice and researc: a sourcebook (4th ed.). Oxford: New York Oxford University Press.

Gordon, C. L. (2006). Intimacy and autonomy development in marriage: An examination of the first five years. University of North Carolina, Chapel Hill.

Hechanova-Alampay, R., Beehr, T. A., Christiansen, N. D., \& Horn, R. K. V. (2002). Adjustment and strain among domestic and international student sojourners: A longitudinal study. School Psychology International, 23(4), 458-474. http://dx.doi.org/10.1177/0143034302234007

Higgins, L. T., Zheng, M., Liu, Y., \& Sun, C. H. (2002). Attitudes to marriage and sexual behavior: A survey of gender and culture differences in China and United Kingdom. Sex Roles, 3(4), 75-89. http://dx.doi.org/10.1023/A:1016565426011

Ho, R. (2006). Handbook of univariate and multivariate data analysis and interpretation with SPSS. CRC Press. http://dx.doi.org/10.1201/9781420011111

Horany, A. A., \& Hassan, S. A. (2011). Marital adjustment among postgraduate students at universities in Malaysia. Elixir Psychology, 37, 3773-3776.

Hovestadt, A. J., Anderson, W. R., Piercy, F. P., Cochran, S. W., \& Fine, M. (1985). A family-of-origin scale. $\begin{array}{lllll}\text { Journal of Marital and Family } & \text { 287-297. }\end{array}$ http://dx.doi.org/10.1111/j.1752-0606.1985.tb00621.x

Ibrahim, M., \& Hassan, S. A. (2011). Quality of Supervision of Ph.D. Program among Public Universities in Malaysia: A research model analysis. Journal of American Science, 7(2), 563-575.

ISAM (2011). Iranian students Association Malaysia. Retrieved from http://www.upmisam.org/news

Kalantarkousheh, S. M., \& Hassan, S. A. (2010). Function of life meaning and marital communication among Iranian spouses in Universiti Putra Malaysia. Procedia Social and Behavioral Sciences, 5, 1646-1649. http://dx.doi.org/10.1016/j.sbspro.2010.07.340

Kameli, M. J. (2008). Investigation in divorce reasons an factors as social threat in Iranian society regarding to present documents and statistics. Journal of Disciplinary Knowledge, 3(35), 179-180.

Kerr, C. (2008). Bowen Family Systems Theory (BFST ) and family art therapy. In J. Hoshino, J. Sutherland, S. T. Parashak \& L. L. McCarley (Eds.), Family art therapy; Foundations of theory and practice. New York: Taylor \& Francis Group.

Kiernan, K. (2000). European perspectives on union formation. In L. Waite, H. Bachrach, M. Christine, E. Hindin \& E. T. A. Thornton (Eds.), The ties that bind: Perspectives on marriage and cohabitation (pp. 40-58). New York: Aldine de Gruyter.

Krauss, S. E., \& Ismail, I. A. (2010). PhD students' experiences of thesis supervision in Malaysia: Managing relationships in the midst of institutional change. The Qualitative Report, 15, 802-822.

Krokoff, L. J. (1989). Predictive validation of a telephone version of the Locke-Wallace Marital Adjustment Test. Journal of Marriage and the Family, 51, 767 - 775. http://dx.doi.org/10.2307/352175

Laham, J. W. (1990). Family of origin Intervention: An intergenerational approach to enhancing marital adjustment. Journal of Contemporary Psychotherapy, 20(4), 211-222. http://dx.doi.org/10.1007/BF00946037

Locke, H., \& Wallace, K. (1959). Short marital-adjustment and prediction tests: Their reliability and validity. Marriage and Family Living, 21, 251-255. http://dx.doi.org/10.2307/348022

Luecken, L. J., Kraft, A., \& Hagan, M. J. (2009). Negative relationships in the family of origin predict attenuated cortisol in emerging adults. Hormones and Behavior, 55(3), 412-417. http://dx.doi.org/10.1016/j.yhbeh.2008.12.007 
Manley, C. M., Wood, P. K., Searight, H. R., Skitka, L. J., \& Russo, J. R. (1994). A latent variable model of the Family-of-Origin Scale for adolescents. Journal of Youth and Adolescence, 23(1), 99-118. http://dx.doi.org/10.1007/BF01537144

Martin, P. D., Specter, G., Martin, D., \& Martin, M. (2003). Expressed attributes of adolescents toward marriage and family life. Adolescence, 38(150), 359-367.

Martin, R. A. (2007). An analysis of marital adjustment, optimal religious functioning, and length of marriage among new, continuing, and graduating students and their non-student spouses at Southwestern Baptist Theological Seminary in Fort Worth, Texas. (Doctoral dissertation). Retrieved from ProQuest Dissertations and Theses. (Order No. AAT 3289562).

Martinson, V. K. (2005). How coming to terms with difficulties in the family of origin positively influences adult children's relationship/marital quality. (Doctoral dissertation). Retrieved from ProQuest Dissertations and Theses. (Order No. AAT 3194366).

Mazer, G. E., Mangrum, O. 1., Hovestadt, A. J., \& Brashear, R. L. (1990). Further validation of the Family of Origin Scale: A factor analysis. Journal of Marital and Family Therapy, 16(4), 423-426. http://dx.doi.org/10.1111/j.1752-0606.1990.tb00060.x

MOHE. (2011). Malaysian Ministry of Higher Education. Retrieved from http://www.mohe.gov.my/portal/en/institution/pihe.html

Patterson, J., Williams, L., Edwards, T. M., Chamow, L., \& Grauf-Grounds, C. (2009). Essential skills in family therapy: From the first interview to termination (2nd ed.). New York: Guilford Press.

Sabatelli, R. M., \& Bartle, S. (2003). Family-of-origin experiences and adjustment in married couples. Journal of Marriage and Family, 65(1), 159-169. http://dx.doi.org/10.1111/j.1741-3737.2003.00159.x

Sanai, B. (2009). Family and marriage scales. Tehran, Iran: Besat Publishing Co.

Shokrkon, H., Khojastemehr, R., Atari, Y., Haghighati, J., \& Shahniyeilagh, M. (2006). Investigation on personality traits, social skills, attachment style and demographic variables as indicator for marital relationship in divorce couples appeals compared with ordinary couples in Ahwaz city, Iran. Journal of Educational Science and Psychology, 3(13), 1-30.

Snyder, C. R., \& Lopez, S. J. (2005). Handbook of positive psychology. New York: Oxford University Press.

Sperry, L. (2004). Assessment of couples and families; Contemporary and cutting-edge strategies. New York: Brunner-Routledge. http://dx.doi.org/10.4324/9780203308271

Steinberg, L., \& Silverberg, S. B. (1986). The vicissitudes of autonomy in early adolescence. Child Development, 57, 841-851. http://dx.doi.org/10.2307/1130361

Topham, G., Larson, J., \& Holman, T. (2005). Family-of-origin predictors of hostile conflict in early marriage. Contemporary Family Therapy, 27(1), 101-121. http://dx.doi.org/10.1007/s10591-004-1973-2

Zaidi, A. U., \& Shuraydi, M. S. (2002). Perceptions of arranged marriages by young Pakistani Muslim women living in a western society. Journal of Comparative Family Studies, 33(4), 495-514. 